\title{
Beneficial effects of Fenugreek seeds (Trigonella foenum graecum L) added in the diet of diabetic rats
}

\author{
Najla Hfaiedh (1), Sabah Dhibi (1), Sakria Mbarki (1), Jean-Claude Murat (2) \& Abdel \\ Fattah Elfeki (1) \\ (1) Laboratoire d'Ecophysiologie Animale, Faculté des Sciences, 3018 Sfax, Tunisie. \\ (2) Laboratoire de Biologie Cellulaire, Faculté de Médecine, 31073 Toulouse, France. \\ Corresponding author: Pr. Najla Hfaiedh \\ E-mail address: najlaharrathi@yahoo.fr \\ Tél: 0021676223 118; Fax:0021676211026 \\ Address : Département de Biologie, Faculté des Sciences, cité Zarroug, 2100 Gafsa, Tunisie.
}

\section{ABSTRACT}

Protective effects of Fenugreek seeds (Trigonella foenum graecum L), added in the diet, upon oxidative stress and dysfunctions in kidney, thyroid and liver of alloxan-diabetic rats were investigated.

In our study, the alloxan-induced diabetes triggered 1) increased levels of glucose, total cholesterol and triglycerides in blood, 2) increased activities of alkaline phosphatase and transaminases in blood, 3) increased levels of creatinine, urea and protein in blood, 4) a decreased level of TSH and an increased level of free thyroxin in plasma.

In addition, an oxidative stress, evidenced by an increase of lipids peroxidation level and superoxide dismutase activity associated with a decrease of glutathione peroxidase and catalase activities in hepatic and renal tissues, was observed.

When Fenugreek seeds powder $(100 \mathrm{~g} / \mathrm{kg})$ was added in the food for 30 days, all this parameters were significantly shifted to more normal values.

In conclusion, fenugreek seeds powder displays beneficial effects upon hepatotoxicity, nephropathy, thyroid dysfunction and oxidative stress in alloxan-diabetic rats. This property could be attributed to the presence of antioxidant components, such as complex polysaccharides and phenolic acids, as confirmed by analyses.

KEY-WORDS: Diabetes; Fenugreek; kidney; oxidative stress; thyroid.

\section{Council for Innovative Research}

Peer Review Research Publishing System

\section{Journal: Journal of Advances in Chemistry}

Vol. 8, No. 2 


\section{INTRODUCTION}

Diabetes is a chronic disease which cannot be completely cured and may develop complications if not properly regulated. Diabetes is primarily characterized by a hyperglycaemia resulting from an absolute or relative insulin deficiency and is associated with long-term complications affecting eyes, kidneys, cardiovascular system, liver and nervous system [1, 2, 3]. The persistent and chronic hyperglycaemia triggers an oxidative stress which generates free radicals and reactive oxygen species (ROS). The overproduction of free radicals and ROS results in 1) enhanced lipid peroxidation, 2) damages to DNA and proteins [4] and 3) exhaustion of the antioxidative defense systems [5]. An alteration of liver functions evidenced by increased levels of AST and ALT (transaminases) activities and troubles in lipid metabolism are often important determinants of severity of the disease $[1,6]$ Renal disease is also one of the most common and severe complications in diabetes [3]. Diabetes mellitus affects the kidney and is the leading cause of diabetic nephropathy. In addition to prominent role played by factors such as oxidative stress, abnormal lipid metabolism and renal accumulation lipids and others, abnormal glycoprotein metabolism have also been proposed to play a pivotal role in the pathogenesis of diabetic nephropathy [7]. Diabetic nephropathy is a major cause of the increased mortality and renal failure itself is responsible for $40 \%$ of mortality. Indeed, there is widespread acceptance of a possible role of reactive oxygen species (ROS), generated as a result of hyperglycaemia in causing many of the secondary complications of diabetes such as nephropathy and liver failure [8]. Thyroxin (T4) is involved in the regulation of many body functions including lipid and carbohydrate metabolism, oxygen consumption, nerve conduction and reproduction [9]. Alterations of its normal levels lead to physiological/clinical abnormalities, such as hypothyroidism or hyperthyroidism which frequently ends by diabetes mellitus.

Several substances are known to exert some anti-diabetic effect by stimulating pancreatic beta-cells and insulin secretion or by restoring peripheral sensitivity to insulin [10]. It is reported that about 800 plants may possess such anti-diabetic potential [11].

Trigonella foenum graecum L (Fenugreek; family: Leguminoseae) is one such plant, whose seeds and leaves are not only used as food but also as an ingredient in traditional medicine [12]. Some of the therapeutic uses of Trigonella foenum graecum L include its use as anti ulcer [13], CNS stimulant [14], immunomodulatory [15], antioxidant [16, 17], antidiabetic [18], anti-inflammatory and anti-pyretic [19]. Hypocholesterolemic and hypolipidemic effects have also been studied [20]. The aqueous extract of fenugreek seeds is known to improve kidney function during diabetes [21]. This plant is known to contain alkaloids, flavonoids, salicylate and nicotinic acid [22]. It was postulated that a fraction of fenugreek seeds (trigonelline), which inhibits AChE activity, could be used for the treatment of Alzheimer's disease [23]. Interestingly, fenugreek seeds have been shown to display a wide range of attractive biological and pharmacologic activities, including, induction of apoptosis, cell cycle arrest, modulation of COX activity, so as immunomodulatory and anti-inflammatory properties [24]

The present study was designed to assess in rats the protective effects of fenugreek seeds (Trigonella foenum graecum) upon diabetes-induced oxidative stress in kidney, liver and thyroid. Examined parameters were 1) plasma levels of glucose, triglycerides and cholesterol 2) activities of alkaline phosphatase (ALP), aspartate aminotransferase (AST) and alanine aminotransferase (ALT) in blood serum, 3) urea, creatinine and proteins levels in blood serum 5) lipids peroxidation level and antioxidant enzymes (SOD, GPX, CAT) activities in liver and kidney 6) plasma T4 and TSH levels. In addition, polysaccharides and phenolic acids contents in fenugreek seeds were measured.

\section{MATERIALS AND METHODS}

\section{2-1 Experimental induction of diabetes}

Rats were i.p. injected with a freshly prepared solution of alloxan monohydrate in saline $(300 \mathrm{mM} \mathrm{NaCl})$ at a dose of $120 \mathrm{mg} / \mathrm{kg}$ body weight as proposed by Al-Shamaony et al. [25]. Since alloxan injection can provoke fatal hypoglycaemia as a result of reactive massive release of insulin, rats were also given orally $5-10 \mathrm{ml}$ of a $20 \%$ glucose solution after $6 \mathrm{~h}$. Rats were then kept for the next $24 \mathrm{~h}$ on a $5 \%$ glucose solution as beverage to prevent too severe hypoglycaemia [25]. After 2 weeks, rats displaying glycosuria and hyperglycaemia (over $2 \mathrm{~g} / \mathrm{l}$ ) were selected for the experiments.

\section{2-2 Experimental design}

3-months-old Wistar male rats, about $150 \mathrm{~g}$ body weight, fed on 15\% proteins food pellets (SICO, Sfax, Tunisia), were kept in a breeding farm, at $22^{\circ} \mathrm{C}$, with a stable hygrometry, under constant photoperiod.

Rats were divided into 4 batches: (C) was control group, (AD) was alloxan-diabetic rats, (AD+Fe) was a group of alloxandiabetic rats treated with Fenugreek seeds $(100 \mathrm{~g} / \mathrm{kg})$, so as to administer about $2 \mathrm{~g}$ of fenugreek powder per day and per rat, $(\mathrm{Fe})$ was a group treated only by fenugreek $(100 \mathrm{~g}$ per $\mathrm{kg}$ ). After 4 weeks, animals from each group were rapidly sacrificed by decapitation in order to minimize the handling stress. The blood serum was obtained by centrifugation (1500 $\mathrm{x} \mathrm{g}, 15 \mathrm{~min}, 4^{\circ} \mathrm{C}$ ) and the kidney and liver were removed, cleaned of fat and weighed. All these samples were stored at $80^{\circ} \mathrm{C}$ until use.

\section{2-3 Biochemical assays}

Level of lipid peroxidation was measured as thiobarbituric acid reactive substances (TBARS), according to Yagi [26]. For the assay, $125 \mu \mathrm{l}$ of supernatant (S1 of kidney or liver) were mixed with $175 \mu \mathrm{l}$ of $20 \%$ trichloroacetic acid containing $1 \%$ butyl-hydroxytoluene and centrifuged $\left(1000 \times \mathrm{g}, 10 \mathrm{~min}, 4^{\circ} \mathrm{C}\right)$. Then, $200 \mu \mathrm{l}$ of supernatant (S2) was mixed with $40 \mu \mathrm{l}$ of $\mathrm{HCl}(0.6 \mathrm{M})$ and $160 \mu \mathrm{l}$ of thiobarbituric acid $(0.72 \mathrm{mM})$ and the mixture was heated at $80^{\circ} \mathrm{C}$ for $10 \mathrm{~min}$. The 
absorbance was measured at $530 \mathrm{~nm}$. The amount of TBARS was calculated using an extinction coefficient of $156 \mathrm{mM}^{-1}$ $\mathrm{cm}^{-1}$ and expressed in nmoles/mg protein.

Catalase (CAT) activity was measured according to Aebi [27]. The reaction mixture (1ml) contained $100 \mathrm{mM}$ phosphate buffer $\left(\mathrm{pH}=7\right.$ ), $100 \mathrm{mM} \mathrm{H}_{2} \mathrm{O}_{2}$ and $20 \mu \mathrm{l}$ (about 1-1.5mg of protein) of kidney or liver extracts. $\mathrm{H}_{2} \mathrm{O}_{2}$ decomposition was followed at $25^{\circ} \mathrm{C}$ by measuring the decrease in absorbance at $240 \mathrm{~nm}$ for 1 min. Enzyme activity was calculated using an extinction coefficient of $0.043 \mathrm{mM}^{-1} \mathrm{~cm}^{-1}$ and expressed in international units (I.U.), i.e., in $\mu \mathrm{moles}$ $\mathrm{H}_{2} \mathrm{O}_{2}$ destroyed /min/mg protein.

The total ( $\mathrm{Cu}-\mathrm{Zn}$ and $\mathrm{Mn}$ ) superoxide-dismutase (SOD) activity was determined by measuring its ability to inhibit the photoreduction of nitroblue tetrazolium (NBT) [28, 29]. One unit of SOD represents the amount inhibiting the photoreduction of NBT by $50 \%$. The activity was expressed as units $/ \mathrm{mg}$ protein, at $25^{\circ} \mathrm{C}$.

Glutathione-peroxidase (GPX) activity was assayed according to the method of Flohe \& Gunzler [30]. The activity at $25^{\circ} \mathrm{C}$ was expressed as $\mu$ moles of $\mathrm{GSH}$ oxidized $/ \mathrm{min} / \mathrm{g}$ protein.

Levels of glucose, cholesterol, triglycerides and the activities of alkaline phosphatase (ALP), aspartate amino transferase (AST), alanine amino transferase (ALT) and concentrations of creatinine, urea and proteins in serum were determined by kit methods (Spinreact).

TSH, free thyroxin (T4) concentrations were determined in serum by microparticle enzyme immunoassay using an automated immunoassay system (AxSYM, Abbott Diagnostics, France).

\section{2-4 Statistical analysis}

Two independent experiments, each carried out on 24 rats, were performed. Data were expressed as mean \pm standard deviation (SD). Statistical significance was assessed by Student's test. $p<0.05$ was considered statistically significant.

\section{2-5 Extraction of fenugreek seeds polysaccharides (FP)}

Powdered fenugreek seeds $(10 \mathrm{~g})$ were dissolved in distilled water $(100 \mathrm{ml})$ and heated at $80^{\circ} \mathrm{C}$ under magnetic stirring for $3 \mathrm{~h}$. The whole extract was filtered and centrifuged at $12000 \times \mathrm{g}$ for $15 \mathrm{~min}$ at $4^{\circ} \mathrm{C}$. The obtained supernatant was overnight precipitated at $4^{\circ} \mathrm{C}$ by adding ethanol (four times the volume of extract solution), followed by centrifugation at $4500 \times g$ for $10 \mathrm{~min}$. The precipitate was dissolved in distilled water $(20 \mathrm{ml})$ and deproteinized by Sevag reagent (chloroform/butanol $4: 1, \mathrm{v} / \mathrm{v}$ ) as described by Navarini et al. [31]. The resulting aqueous fraction was again precipitated by ethanol as described above. After centrifugation, the precipitate was washed with anhydrous ethanol, dissolved in distilled water and extensively dialyzed against double-distilled water for three days. The purified fenugreek polysaccharides (FP) were then precipitated by adding ethanol and lyophilized.

\section{2-6 Fourier transformation infra red (FT-IR) spectral analysis of polysaccharides}

Infrared spectra of the FP were recorded with FT-IR (Shimadzu, FTIR-8400S, CE) spectrometer equipped with IRsolution 1.10 Shimadzu software in the range of $4000 / 500 \mathrm{~cm}^{-1}$. FT-IR scans were collected on completely dried thin films of FP cast on $\mathrm{KBr}$ discs. The spectra covered the infrared region $4000-500 \mathrm{~cm}^{-1}$, the number of scans per experiment was 10 and resolution was $6 \mathrm{~cm}^{-1}$.

\section{2-7 Extraction of fenugreek seeds phenolic acids (FPA)}

Powdered fenugreek seeds $(1 \mathrm{~g})$ were mixed with $10 \mathrm{ml}$ of $80 \%$ methanol, and kept under magnetic stirring at room temperature for $24 \mathrm{~h}$. To improve extractability, fenugreek extract were sonicated for $5 \mathrm{~min}$, vortexed and then centrifuged at $10000 \times g$ for $10 \mathrm{~min}$. The upper layer were then treated with acetone $(1: 4 \mathrm{v} / \mathrm{v})$ and centrifuged for $10 \mathrm{~min}$ at $10000 \times g$ to precipitate pigments. Prior to HPLC analysis, supernatant was sonicated for 5 min to degas the sample and then filtrated through $0.45 \mu \mathrm{m}$ nylon filters (Carl Roth $\mathrm{GmbH}$, Karlsruhe, Germany).

\section{2-8 HPLC analysis conditions}

The HPLC analysis of the FPA was carried out using a Varian Prostar HPLC equipped with a C-18 reverse phase column (Varian, $150 \mathrm{~mm} \times 4.6 \mathrm{~mm}$, particle size $5 \mu \mathrm{m}$ ), a ternary pump (model Prostar 230) and a Prostar 330 diode array detector at an isocratic elution. Eluant was set as Water/Acetonitrile/Methanol (50/25/25 v/v), the flow rate was $1 \mathrm{ml} \mathrm{min}^{-1}$ and the injection volume was $20 \mathrm{ml}$ at $25^{\circ} \mathrm{C}$. Gallic, protocatechic and caffeic acids were used as phenolics acids standards. The identification were performed at $280 \mathrm{~nm}$ based on the comparison with the retentions times of standards and by coinjection.

\section{RESULTS}

\section{3-1 Blood glucose, cholesterol and triglycerides levels}

Our data show a significant increase of glucose, triglycerides and total cholesterol levels in diabetic rats as compared to controls. Fenugreek treatment restored these levels to almost control values after 4 weeks of treatment (Table 1). 


\section{3-2 Serum markers of liver and kidney damages}

Alkaline phosphatase (ALP), Aspartate aminotransferase (AST) and Alanine amino transferase (ALT) are released into the blood when certain organs or tissues are injured. As shown Fig 1, these activities were significantly higher in diabetic rats than in controls. Hyperglycemia also induced kidney damages evidenced in serum by a significant increase of creatinine, urea and proteins levels (Fig. 2). Hyperglycemia also reduced TSH levels and increased T4 levels in serum (Fig. 3). When the diabetic rats were treated with Fenugreek, all theses biomarkers were restored to almost normal values.

\section{3-3 Oxidative damages}

TBARS levels in hepatic and renal tissues were increased in diabetic rats as compared to controls by $+125 \%$ and $+152 \%$, respectively (Tables 2 and 3). Administration of Fenugreek significantly reduced these TBARS levels.

\section{3-4 Antioxidant activities}

Activities of enzymes which protect against oxidative stresses, i.e., CAT and GPX were found to be respectively reduced by $-57 \%$ and $-46 \%$ in liver and by $-37 \%$ and $-57 \%$ in kidney. SOD activity was increased respectively by $+102 \%$ in liver and by $+58 \%$ in kidney of diabetic rats, as compared to controls (Tables 2 and 3 ). These changes, revealing a failing defence against an oxidative stress, were largely corrected in animals treated by Fenugreek.

\section{3-5 FT-IR spectral analysis of fenugreek seeds polysaccharides (FP)}

As shown in Fig. 4, the FT-IR spectra of FP displayed a broad stretching intense peak at $3390 \mathrm{~cm}^{-1}$ which is the characteristic absorption of hydroxyl groups, followed by weak $\mathrm{C}-\mathrm{H}$ stretching bands at $2929 \mathrm{~cm}^{-1}$ [32]. Uronic acids were characterized by the carboxylic group which could lead to three absorbance peaks. The band towards $1656 \mathrm{~cm}^{-1}$ was attributed to the stretching vibration of $\mathrm{C}=\mathrm{O}$ in protonated carboxylic acids. Two peaks towards 1543 and $1402 \mathrm{~cm}^{-1}$ were attributed to the absorbance of the $\mathrm{COO}^{-}$deprotonated carboxylic group [33]. The other peaks observed in the FT-IR spectrum of FP were assigned as $1239 \mathrm{~cm}^{-1}$, C-O stretching band of complex polysaccharides; $1154 \mathrm{~cm}^{-1}$, stretching of C-O-C group of polysaccharides; $1076 \mathrm{~cm}^{-1}$, stretching of $\mathrm{C}-\mathrm{O}-\mathrm{H}$ group of polysaccharides [34]. The peak at $1027 \mathrm{~cm}$ could be characteristic of rhamnose. The peak observed at $871 \mathrm{~cm}^{-1}$ was characteristic of $\beta-D-g l u c o s e ~[35]$. The peak at $532 \mathrm{~cm}^{-1}$ was due to $\mathrm{O}-\mathrm{H}$ out-of-plane vibration [36].

\subsection{HPLC analysis of fenugreek seeds phenolic acids (FPA)}

As shown in Fig.5, the HPLC analysis of FPA revealed the presence of phenolic acids. There were three phenolic acids identified in FPA including protocatechic, gallic and caffeic acids with the respectively retention times $4.741 \mathrm{~min}, 8.835 \mathrm{~min}$ and $15.536 \mathrm{~min}$. The HPLC elution profile of phenolic acids (Fig. 5) also showed seven peaks of unknown compounds. Such abundance in antioxidant compounds might confer to the fenugreek seeds extract an in vivo beneficial effect.

\section{DISCUSSION}

Diabetes mellitus is a heterogeneous metabolic disorder diagnosed by hyperglycemia, afflicting a large proportion of the population all over the world [37]. This serious health problem results from impaired insulin secretion or defects in insulin action, or both [38]. This hyperglycaemia leads to the over-production of free radicals and the non-enzymatic glycation of proteins which are responsible for adverse effects, especially in kidney and liver.

In the present study, hyperglycemia due to uncontrolled glucose regulation is considered as the causal link between diabetes and liver damage which is evidenced by 1) increased levels of cholesterol and triglycerides and 2) higher activities of alkaline phosphatase and transaminases. These results are confirmed by the observed increase of serum enzymes (AST, ALT, ALP) activities which reflects liver damage in diabetic rats [1,6]. A number of studies emphasizes that alterations in glucose metabolism leads to hyperglycemia-induced cell damage by four key metabolic pathways, viz, increased polyols pathway flux, increased glycation of proteins, increased hexosamine pathway flux and activation of protein kinase $\mathrm{C}$ isoforms [39]. A reduction in glomerular filtration rate objectified by an increased level of plasma creatinine, urea and protein concentrations were determined in diabetic rats as markers of progressive nephropathy. The increase of serum creatinine and urea in diabetic rats may be due to metabolic disturbances reflected by the high activities of xantine oxidase, lipid peroxidation, and increased triacylglycerol and cholesterol levels [40]. The increase of blood proteins level is a major predictor of glomerular injury. Our findings corroborate the results of previous investigations carried out in streptozotocin-diabetic rats $[1,7]$.

Shifts in a variety of biological parameters can be attributed to a general oxidative stress triggered by alloxan treatment and the subsequent hyperglycaemia which degrades non-enzymatic antioxidant defences and allows reactive oxygen species to damage cells and tissues. The reduced activities of CAT and GPX, the increased rate of lipid peroxidation and and the high activity of superoxide dismutase in liver and kidney of diabetic rats contribute to the worsening of the oxidative stress. In diabetic rats, reactive oxygen species (ROS) generate damage in thyroid, as evidenced by a decrease in TSH levels and an increase of T4 levels, as compared to controls. In fact, thyroid dysfunction could also be explained by hyperglycemia which is associated with hepatotoxicity and renal dysfunction. Hyperthyroidism is typically associated with a failing glycemic control and an increased insulin requirement. There is due to increased gluconeogenesis, rapid gastrointestinal glucose absorption, and increased resistance to insulin. Indeed, thyrotoxicosis may unmask latent diabetes. Restoration of euthyroidism will lower blood glucose as reported by Fry [40] who showed that hyperthyroidism, if not properly treated, sometimes ends up with health problems such as diabetes mellitus and cardio-vascular diseases. 
The results presented in this study show that fenugreek extract, administered per os, reduced liver, kidney and thyroid damages appearing in diabetic rats. In fact, all hepatic biomarkers (AST, ALT, ALP activities), blood glucose, cholesterol and triglycerides levels and renal biomarkers (creatinine, urea and protein) were restored to almost normal values. This confirms previous findings by Eidi et al. and Hamden et al. [1, 18] ho showed that fenugreek extract decreased levels of uric acid, urea and creatinine in blood, and reduced transaminases activities in diabetic rats. From these results, one might suppose that fenugreek seed extract regulate serum T4 and TSH concentrations which, in turn, regulate glucose metabolism. Hyperthyroidism was found to increase glycogenolysis [41] and these authors suggested that the hypoglycaemic effect of fenugreek seed could be the result of a decrease in triiodothyronine (T3) concentration.

Fenugreek extract reduced lipid peroxidation and enhanced antioxidant state (superoxide dismutase, glutathione peroxidase and catalase) by its ability to scavenge free radicals as confirmed by Naidu et al. [42]. The beneficial activity of fenugreek appears to be directly due to the presence of some bioactive compounds such as 4-hydroxy isoleucine known to facilitate insulin secretion [43]. In fact, hydroxy isoleucine displayed also an insulinotropic property in vitro, stimulated insulin secretion in vivo and improved glucose tolerance in rat model of type 2 diabetes mellitus [44]. In the current study we can associate the protective effects of fenugreek seeds to the presence of complex polysaccharides (fibres) and phenolic acids (protocatechic, gallic and caffeic acids). These polysaccharides are not digested by the body. Soluble fibres lower serum cholesterol and help to reduce the risk of heart attack and colon cancer. These fibres dissolve in the gut to form a viscous gel which lowers the absorption of released glucose [42]. The fibres thus reduce diabetes complications as reported by Kumar et al. [21]. Fenugreek is also a valuable source of natural antioxidants and natural ingredients such as phenolic acids. A number of studies reported the relation between chemical structure of phenolics acids and their ability to reduce free radicals by releasing a proton by the hydroxyle group [23]. Our study is supported by other findings showing that many micronutriments such as phenolic acids, dietary fibres, saponins and proteins, all displaying some antidiabetic effects, are components of fenugreek $[42,44]$.

\section{CONCLUSION}

Fenugreek seeds, given in diet, display protective effects in liver, kidney, and thyroid, as evidenced in diabetic rats. They also reduce the oxidative stress. We can propose fenugreek seeds as a valuable food additive, especially in cases of diabetes and hyperthyroidism.

\section{DECLARATION OF INTEREST}

The authors declare no conflict of interest.

\section{ACKNOWLEDGEMENT}

The present work was supported by the Laboratory of Physiology, Faculty of Sciences at Sfax and the Unity of the mixed services, Faculty of Sciences at Gafsa. We thanks very much the unity of common services in findings in Faculty of Sciences at Gafsa.

\section{REFERENCES}

[1] A Eidi, M Eidi, M Sokhteh. Nutrition Research. 27 (2007)728-733.

[2] M.S. Farvid, F. Siassi, M. Jalali, M. Hosseini, N. Saadat. Diabetes Research and Clinical Practice. 65 (2004) 21-28.

[3] M. Thomson, Z.M. Al Amin, K.K. Al-Qattan, L.H. Shaban, Muslim. Ali. Int JDiabetes \& Metabolism. 15 (2007) 108115.

[4] D. Dreher, A.F. Junod. Eur J Cancer 32A (1996) 30-8.

[5] H.D. Hammers, S. Martin, K. Fedesrlin, K. Geisen, M. Brownlle. Diabetes

40 (1991) 405-12.

[6] K. Hamden, B. Jaouadi, N. Zarai, T. Rebai, S. Carreau, A. Elfeki.

J Physiol Biochem. 67 ( 2011) 121-128.

[7] G. Saravanan, P. Ponmurugan, G.P. Senthilkumar, T. Rajarajan.

Phytomedicine 17 (2010) 1086-1086.

[8] E.O. Farombi, O.O. Ige. Fund Clin Pharmacol 21 (2007) 601-609.

[9] W.F. Ganong. Review of medical physiology. Appleton and Lange, Connecticut, pp. (1995) 290-305.

[10] Y.B. Lambardo, A.G. Chicco. The Journal of Nutritional Biochemistry. 17 (2006) 1-13.

[11] J.K. Grover, S. Yadav \& V. Vats. Journal of Ethnopharmacology 81 (2002) 81-100.

[12] R.D. Sharma, A. Sarkar, D.K. Hazra, B. Misra, J.B. Singh, B.B. Maheswari. Phytotherapy. Res.10 (1996) $512-520$.

[13] R.S. Pandian, C.V. Anuradha, P. Viswanathan. Journal of Ethnopharmacology 81 (2002) 393-397. 
[14] B. Natrajan, A. Muralidharan, R. Satish, R. Dhananjayan. J Nat Rem (2007)160-165.

[15] B.H. Bilal, H. Rizwarul, P. Suhel, P. Suwarna, S. Iqbal, S. Raisuddin. Int. Immunopharmacol 3 (2003) 257-265.

[16] S. Kaviarasan, G.H. Naik, R. Gangabhagirathi, C.V. Anuradha, K.I. Priyadarsini. Food Chemistry 103 (2007) 31-37.

[17] N. Hfaiedh, H. Alimi, J.C. Murat, E. Abdelfattah. Genral Physiology and Biophysics 31 (2012) 423-430.

[18] K. Hamden, B. Jaouadi, T. Salami, S. Carreau, A. Elfeki. Biotechnol Bioprocess. (2010). in press.

[19] A. Ahmadiani, M. Javan, S. Semnanian, E. Barat, M. Kamalinejad. Journal of Ethnopharmacology 75 (2001) 283-286.

[20] V. Vats, S.P. Yadav, J.K. Grover. JEthnopharmacol 85 (2003) 2-3.

[21] G.S. Kumar, A.K. Shetty, K. Sambaiah, P.V. Salimath. Nutrition Research. 25 (2005) 1021-1028.

[22] R. Kamal, R. Yadav. Journal of phytological research. 4 (1991) 161-165.

[23] N. Satheeshkumar, P.K. Mukherjee, S. Bhadra, B.P. Saha. Phytomedicine 17 (2010) 292-295.

[24] L. AL-Shamaony, S.M. Al-Khazraji, H.A. Twaiji. JEthnopharmacol 43 (1994) 167.

[25] M.P. Gupta, N.G. Solis, M. Esposito, S. Sanchez. J.Ethnopharmacol 10 (1984) 323.

[26] K. Yagi. Biochem Med 15 (1976) 212-216.

[27] H. Aebi. Catalase in vitro. Methods Enzymol. 105 (1984) 121-126.

[28] Y. Sun, L.W. Oberley, Y. Li. Clin Chem 34 (1988) 497-500.

[29] I. Durak, Z. Yurtarslanl, O. Canbolat, O. Akyol. Clin Chim Acta 214 (1993)103-104.

[30] L. Flohe, W.A. Gunzler. Methods Enzymol 105 (1984) 114-121.

[31] L. Navarini, R. Gilli, V. Gombac, A. Abatangelo, M. Bosco, R. Toffanin. Carbohydrate Polymers. 40 (1999) 71-81.

[32] W. Xu, F. Zhang, Y. Luo, L. Ma, X. Kou, K. Huang. Carbohydrate Research. 344 (2009) 217-222.

[33] G. D. Manrique, F.M. Lajolo. Postharvest Biology and Technology. 25 (2002) 99-107.

[34] S.A. Naqvi, M.M. Khan, M. Shahid, M.J. Jaskani, I.A. Khan, M. Zuber, \& K.M. Zia. Carbohydrate Polymers. 83 (2011) 623-628.

[35] M. Zhao, N. Yang, B. Yang, Y. Jiang, G. Zhang. Food Chemistry 105 (2007) 1480-1486.

[36] A. Chiovitti, A. Bacic, D.J. Craik, S.L.A. Munro, G. T. Kraft, \& M.L. Liao. Carbohydrate Research 299 (1997) 229-243.

[37] P. Zimmet, K.G.M.M. Alberti, J. Shaw. Nature. 414 (2001) 782-7.

[38] O. Khookhor, Q. Bolin, Y. Oshida, Y. Sato. Diab. Res. Clin. Pract. 75 (2007) 135-140.

[39] A.P. Rolo, C.M. Palmeira. Toxicol.Appl.Pharmacol 212 (2006) 167-178.

[40] Fry. Thyroid related diseases and their treatment. Eastern Pharma. 1993) 27-29.

[41] S. Panda, P. Tahiliani, A. Kar. Pharmacol Res. 40 (1999) 405-409.

[42] M.M. Naidu, B.N. Shyamala. J.P. Naik, G. Sulochanamma, P. Srinivas.

LWT- Food Science and Technology 44 (2001) 451-456.

[43] Y. Sauvaire, P. Petit, C. Broca, M. Manteghetti, Y. Baissac, J. Fernandez-Alvarez, et al. Diabetes. 47 (1998) $206-$ 10.

[44] S. Mohamed, A. Taha, R.N.K. Bamezai, S.F. Basir, N.Z. Baquer. Clinica chimica Acta 342 ( 2004)105-114. 
TABLE 1. Blood glucose $(\mathrm{mmol} / \mathrm{l})$, cholesterol $(\mathrm{mmol} / \mathrm{l})$, and triglycerides $(\mathrm{mmol} / \mathrm{l})$ levels after 4 weeks of treatment in: controls $(C)$, alloxan-treated rats $(A D)$, fenugreek treated rats $(F e)$ and diabetic's rats treated with fenugreek $(A D+F e)$.

\begin{tabular}{lcccc}
\hline Group & C & AD & Fe & AD+Fe \\
\hline Glucose & $7.15 \pm 0.2$ & $9.12 \pm 0.62^{* *}$ & $7.42 \pm 0.61^{++}$ & $8.05 \pm 0.25^{++}$ \\
Cholesterol & $1.3 \pm 0.25$ & $1.95 \pm 0.12^{* *}$ & $1.45 \pm 0.12^{++}$ & $1.32 \pm 0.29^{++}$ \\
Triglycerides & $1.65 \pm 0.13$ & $2.12 \pm 0.15^{* *}$ & $1.58 \pm 0.15^{++}$ & $1.71 \pm 0.19^{++}$ \\
\hline
\end{tabular}

Values are the mean of 6 measurements \pm SD.

** Significant difference as compared to control rats $(C)(p \leq 0.01)$

${ }^{++}$Significant difference when comparing $\mathrm{Fe}$ and $(\mathrm{AD}+\mathrm{Fe})$ groups to $\mathrm{AD}$ group.
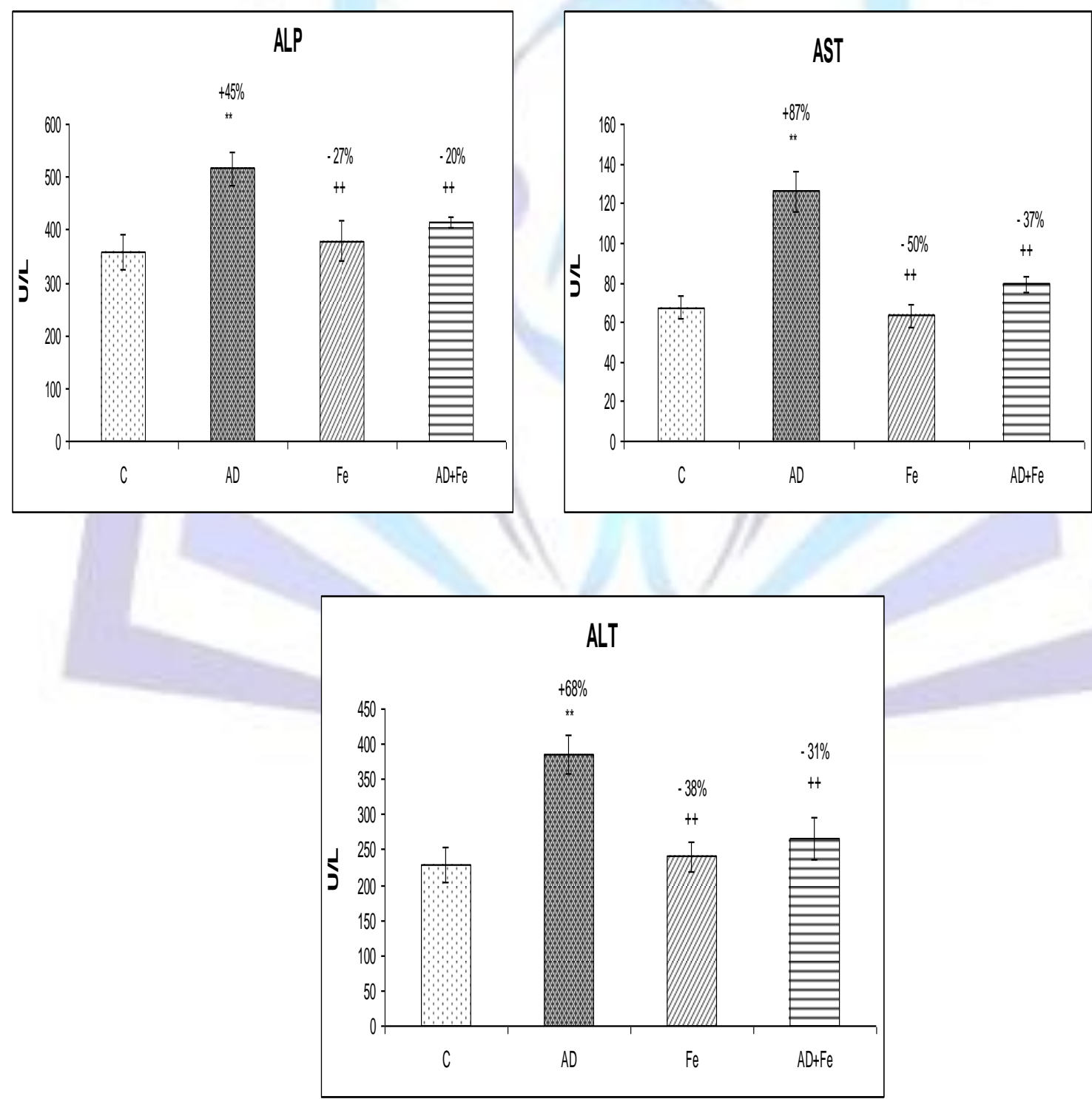

FIGURE 1. Plasma aspartate aminotransferase (AST), alanine aminotransferase (ALT) and alkaline phosphatase (ALP) activities $(\mathrm{U} / \mathrm{l})$ after 4 weeks of treatment in: controls $(C)$, alloxan-treated rats $(A D)$, fenugreek treated rats $(\mathrm{Fe})$ and diabetic rats treated with fenugreek $(A D+F e)$. 
Values are the mean of 6 measurements $\pm S D$.

** Significant difference as compared to control rats $(C)(p \leq 0.01)$

${ }^{++}$Significant difference when comparing Fe and $(A D+F e)$ groups to $A D$ group.
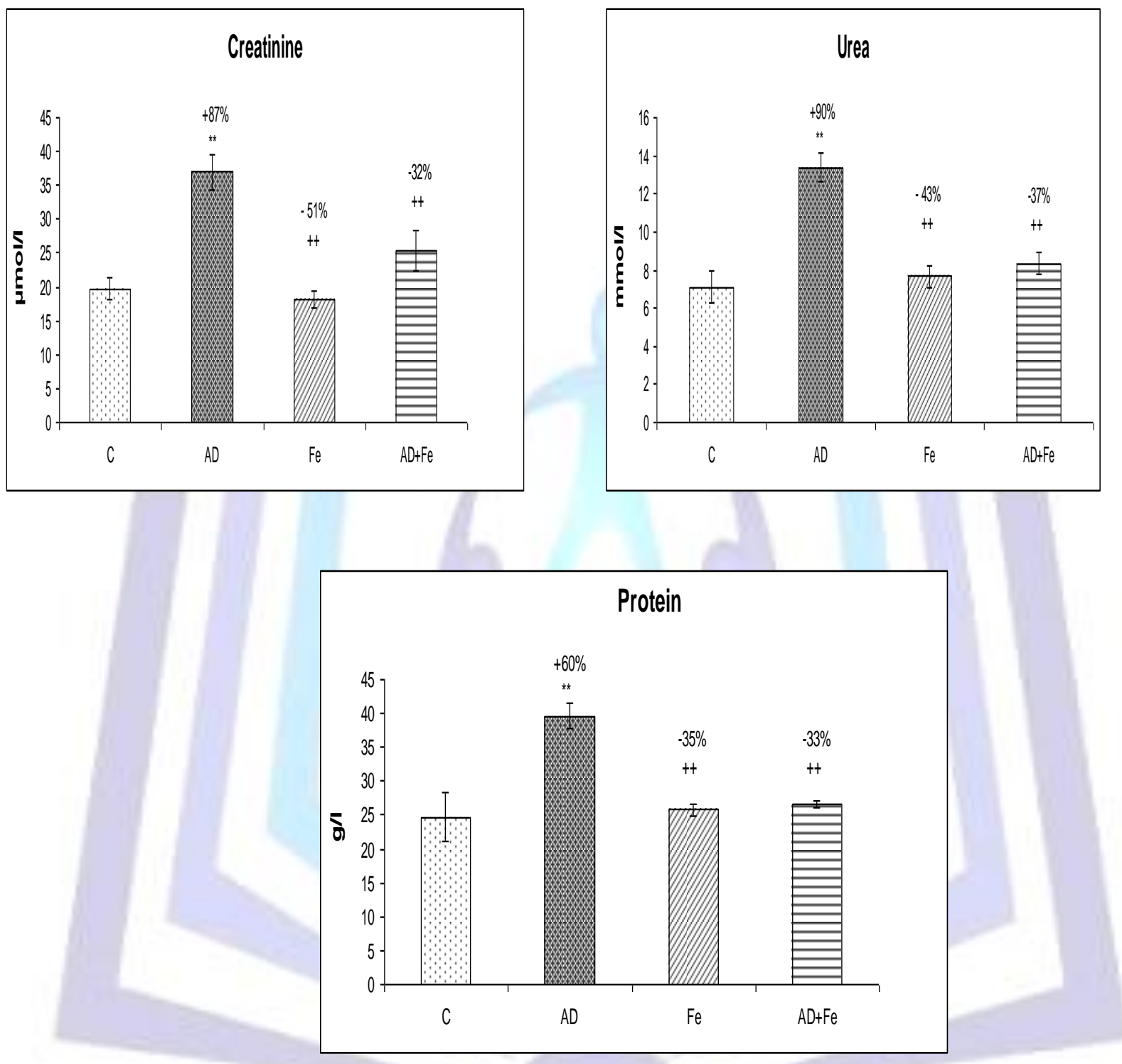

FIGURE 2. Serum creatinine $(\mu \mathrm{mol} / \mathrm{l})$, urea $(\mathrm{mmol} / \mathrm{l})$ and proteins $(\mathrm{g} / \mathrm{l})$ levels after 4 weeks of treatment in: controls $(C)$, alloxan-treated rats $(A D)$, fenugreek treated rats $(F e)$ and diabetic rats treated with fenugreek $(A D+F e)$.

Values are the mean of 6 measurements \pm SD.

** Significant difference as compared to control rats $(C)(p \leq 0.01)$

${ }^{++}$Significant difference when comparing Fe and (AD+Fe) groups to AD group 

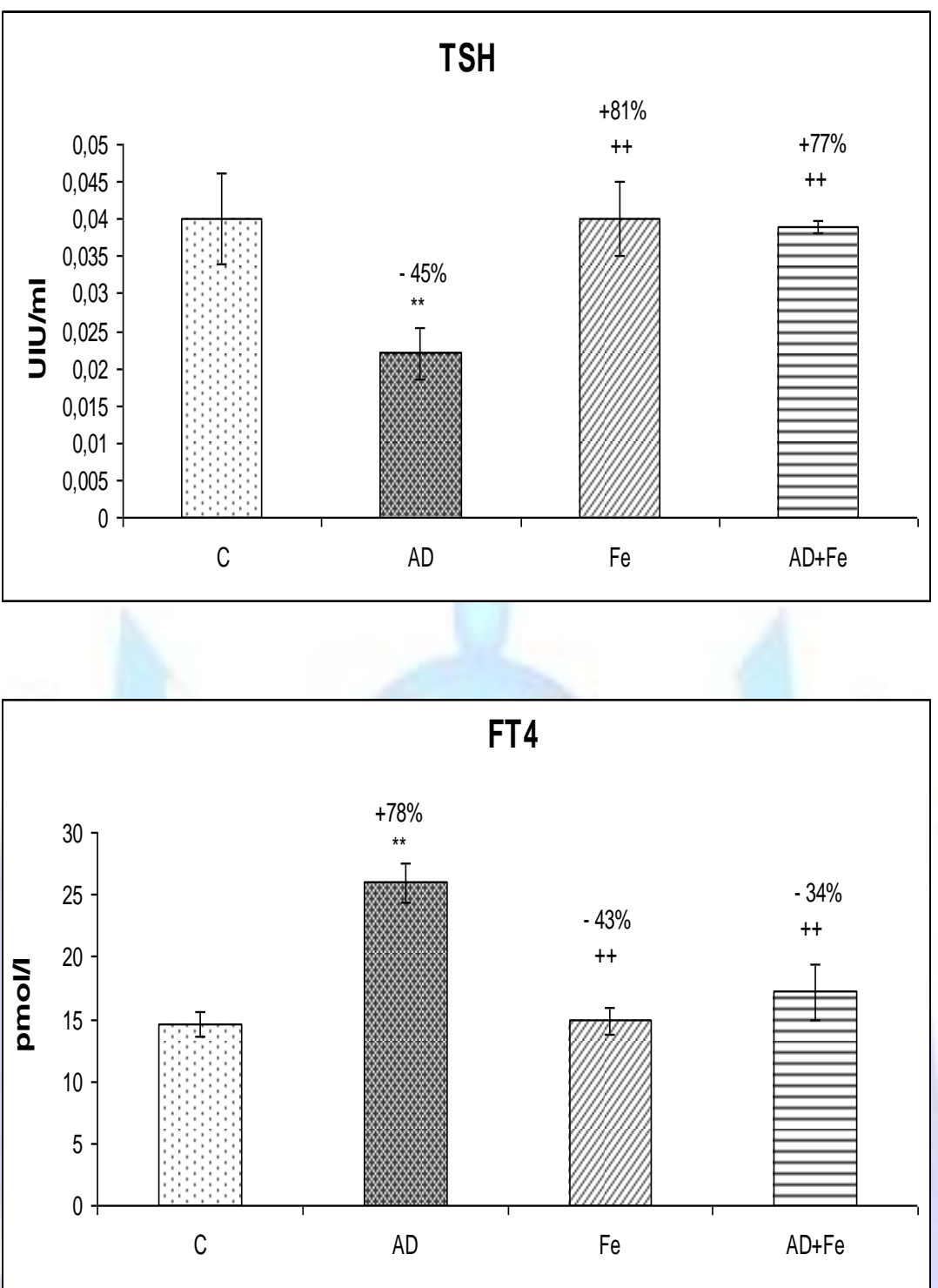

FIGURE 3. Serum TSH (IU/ml) and free thyroxin (pmol/l) levels after 4 weeks of treatment in: controls (C), alloxan-treated rats $(A D)$, fenugreek treated rats $(F e)$ and diabetic rats treated with fenugreek ( $A D+F e)$.

Values are the mean of 6 measurements \pm SD.

** Significant difference as compared to control rats $(C)(p \leq 0.01)$

${ }^{++}$Significant difference when comparing $\mathrm{Fe}$ and $(A D+F e)$ groups to $A D$ group. 


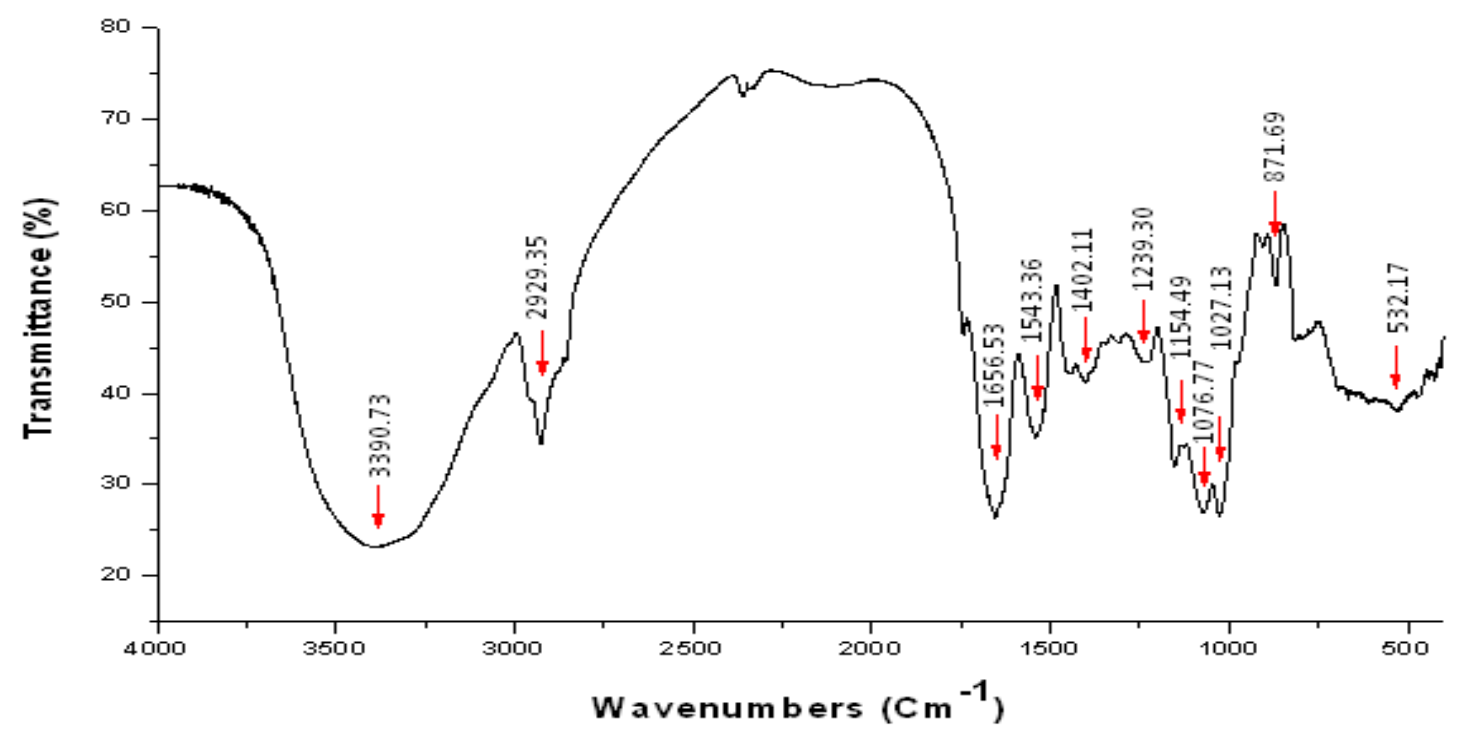

FIGURE 4. Infrared spectra of the polysaccharides extracted from Fenugreek seeds, recorded in the frequency range $4000-500 \mathrm{~cm}^{-1}$.

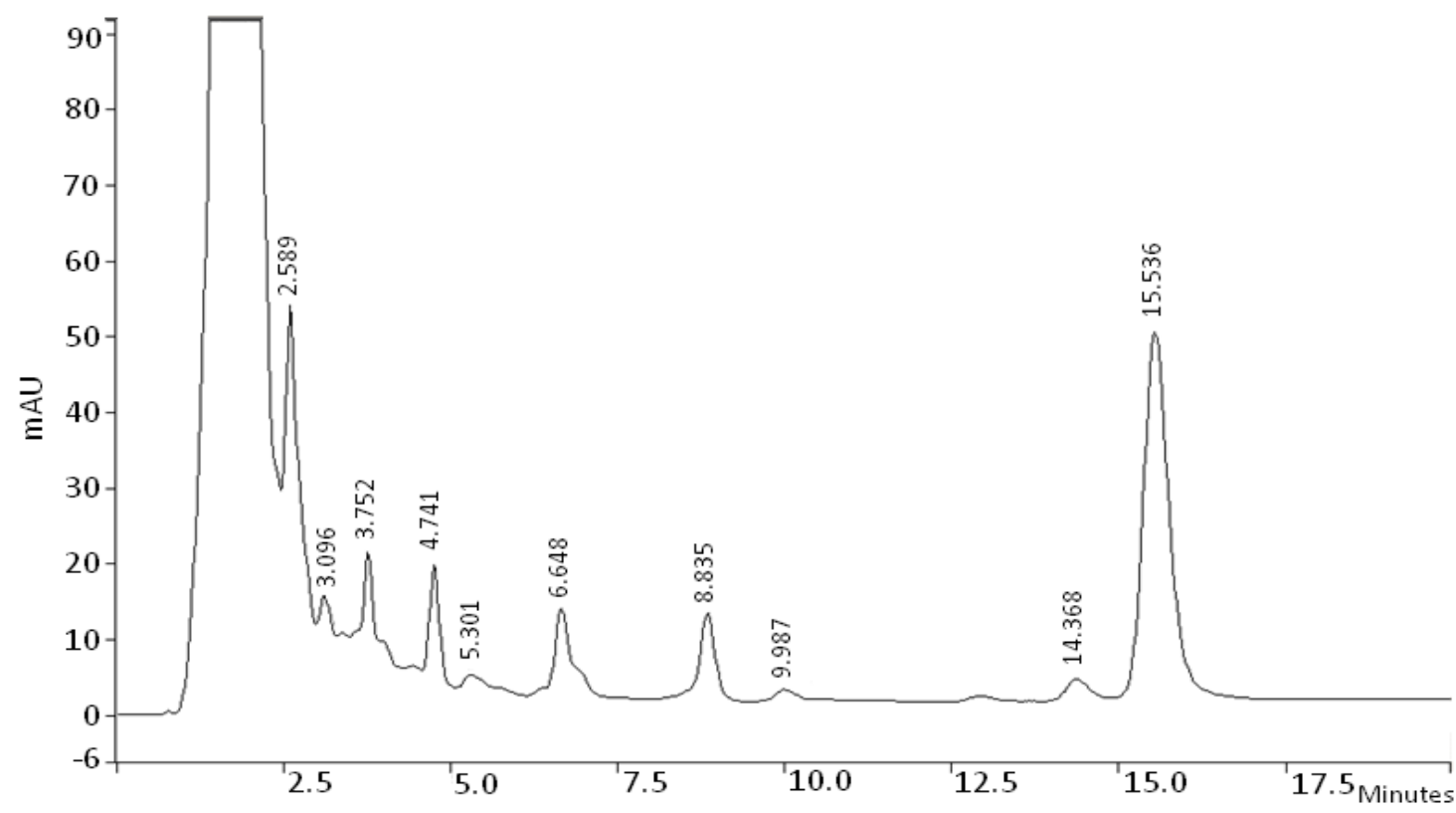

FIGURE 5. HPLC elution profile of phenolic acids $(\lambda=280 \mathrm{~nm})$ from Fenugreek seeds. Three phenolic acids identified in fenugreek seeds extract including protocatechic, gallic and caffeic acids with the respectively retention times 4.741 min, $8.835 \mathrm{~min}$ and $15.536 \mathrm{~min}$. The HPLC analyses were performed using a Varian Prostar HPLC equipped with a reverse phase C-18 column (Varian, $150 \mathrm{~mm} \times 4.6 \mathrm{~mm}$, particle size $5 \mu \mathrm{m}$ ) on conjunction with isocratic elution:

Water/Acetonitrile/Methanol (50/25/25 v:v). The flow rate was $1 \mathrm{ml} \mathrm{min}^{-1}$ and the injection volume was $20 \mu \mathrm{l}$ at $25^{\circ} \mathrm{C}$. 
TABLE 2. TBARS (nmol/mg protein) levels and activities of SOD (U/mg protein), GPX (U/mg protein) and CAT (U/mg protein) in liver after 4 weeks of treatment in: controls $(C)$, alloxan-treated rats (AD), fenugreek treated rats $(F e)$ and diabetic rats treated with fenugreek $(A D+F e)$.

\begin{tabular}{lrrrr}
\hline Group & C & AD & Fe & AD+Fe \\
\hline TBARS & $0.51 \pm 0.11$ & $1.15 \pm 0.19^{* *}$ & $0.47 \pm 0.02^{++}$ & $0.68 \pm 0.086^{++}$ \\
SOD & $3.99 \pm 0.42$ & $8.07 \pm 0.22^{* *}$ & $4.25 \pm 0.52^{++}$ & $5.67 \pm 0.47^{++}$ \\
GPX & $4.7 \pm 0.53$ & $2.52 \pm 0.6^{* *}$ & $4.3 \pm 0.74^{++}$ & $3.6 \pm 0.59^{++}$ \\
CAT & $12.95 \pm 0.82$ & $5.57 \pm 0.84^{* *}$ & $10.87 \pm 1.03^{++}$ & $9.6 \pm 1.25^{++}$ \\
& & & & \\
\hline
\end{tabular}

Values are the mean of 6 measurements \pm SD.

** Significant difference as compared to control rats $(C)(p \leq 0.01)$

${ }^{++}$Significant difference when comparing $F e$ and $(A D+F e)$ groups to $A D$ group.

TABLE 3. TBARS ( $\mathrm{nmol} / \mathrm{mg}$ protein) levels and activities of SOD (U/mg protein), GPX (U/mg protein) and CAT (U/mg protein) in kidney after 4 weeks of treatment in: controls $(C)$, alloxan-treated rats (AD), fenugreek treated rats $(\mathrm{Fe})$ and diabetic rats treated with fenugreek $(A D+F e)$.

\begin{tabular}{lrrrr}
\hline Group & C & AD & AD+Fe \\
\hline TBARS & $0.56 \pm 0.13$ & $1.4 \pm 0.17^{* *}$ & $0.49 \pm 0.07^{++}$ & $0.66 \pm 0.02^{++}$ \\
SOD & $6.1 \pm 0.84$ & $9.67 \pm 1.35^{* *}$ & $5.75 \pm 0.95^{++}$ & $5.37 \pm 0.43^{++}$ \\
GPX & $5.3 \pm 0.47$ & $2.25 \pm 0.5^{* *}$ & $4.9 \pm 0.73^{++}$ & $4.55 \pm 0.58^{++}$ \\
& & & & \\
CAT & $20 \pm 3.63$ & $12.5 \pm 1.29^{* *}$ & $20.1 \pm 1.9^{++}$ & $18.37 \pm 1.17^{++}$ \\
\hline
\end{tabular}

